\title{
Covid-19 Pandemisi Sirasında Sporda Kriz Yönetiminin Bir Parçası Olarak Espor Kullanımı
}

\author{
Mertkan Üçüncüoğlu* \\ Hamdi Özdemir** \\ Veli Ozan Çakır**
}

Öz

Tahmin edilemeyen bir şekilde ortaya çıan ve kısa sürede etkisini geniş çapta gösteren Covid-19 pandemisi birçok sektörde olduğu gibi spor endüstrisinde de krize neden olmuştur. Dünya genelinde uygulanan sokağa çıkma kısıtlamalarıyla birlikte spor müsabakaları durma noktasına gelmiştir. Spor müsabakaları normalleşme süreciyle birlikte yeniden başlasa dahi stadyumlara seyirci alınmasına izin verilmemiştir. Bu nedenle spor organizasyonları ne zaman tam anlamıyla sonlanacağı henüz belli olmayan pandemi süreci boyunca kitlelere ulaşmak için farklı yollar aramışlardır. Fiziki olarak kitlelerine ulaşma fırsatı yakalayamayan spor organizasyonlarının son yıllarda giderek gelişen espor olgusunu çalışmalarına adapte ettikleri görülmektedir. Spor organizasyonlarının Covid-19 salgını sürecinde yaşanan kriz döneminde esporu nasıl kullandıklarını ve kriz yönetiminin bir parçası olarak nasıl ele aldıklarını ortaya koymaktır. Sonuç olarak espor etkinliklerinin, spor organizasyonlarına kitlelere ulaşabilme ve onlarla ilişkilerini canlı tutabilme adına farklı bir içerik oluşturma imkânı sağladığı görülmüştür.

Anahtar Kelimeler: COVID-19, Espor, Salgın, Spor Endüstrisi, Kriz Yönetimi

* Doktora öğrencisi, İstanbul Üniversitesi Cerrahpaşa, Lisansüstü Eğitim Enstitüsü, Spor Yönetim Bilimleri ABD, İstanbul. mertkanucuncuoglu@gmail.com ORCID: 0000-0002-5589-2857

** Arş. Gör. İstanbul Üniversitesi Cerrahpaşa, Spor Bilimleri Fakültesi, İstanbul. hamdiozdemir@istanbul.edu.tr ORCID: 0000-0001-7684-7898

*** Doç. Dr. Alanya Alaaddin Keykubat Üniversitesi, Spor Bilimleri Fakültesi, Antalya. ozan.cakir@alanya.edu.tr ORCID: 0000-0001-7996-2138 


\begin{abstract}
The Covid-19 pandemic emerged without warning and caused a crisis in both the sports industry and in countless other sectors. The resulting curfews mandated around the world have forced sports competitions to be put on hold. Although sports competitions resumed during the normalization process in Turkey, spectators have not been allowed in stadiums. Consequently, sports organizations have sought unique means to reach the masses during the ongoing pandemic. Sports organizations have adopted esports phenomenon over recent years. The main purpose of this study is to reveal how sports organizations have used esports during thisperiod and how they have incorporated it into their crisis management actions. As a result, esports events have been observed to facilitate the opportunity to create a different medium for sports organizations to reach the masses and maintain their relations with them.
\end{abstract}

Keywords: Covd-19, Esports, Sports Industry, Pandemic, Crisis Management

\title{
Giriş
}

İnsanlık tarihi boyunca salgınlar, savaşlar, ekonomik krizler vb. birçok olağanüstü durum meydana gelmiştir. Kısa sürede tüm dünyayı etkisi altına alan ve toplumsal hayatın dengesini bozan Covid-19 pandemisi içinde bulunduğumuz yüzyılın en önemli olaylarından biri olarak karşımıza çıkmaktadır. Koronavirüs hastalığı (COVID-19) yeni keşfedilen bir koronavirüsün neden olduğu bulaşıcı bir hastalıktır (WHO, 2020a) ve 11 Mart 2020 tarihinde Dünya Sağllk Örgütü tarafından pandemi olarak değerlendirilmiştir (WHO, 2020b). Covid-19 virüsü Kasım 2020 itibariyle tüm dünyada 62,3 milyondan fazla kişiye bulaşmış, 1,4 milyondan fazla kişinin ölümüne neden olmuştur (news.google.com, 2020). Özellikle virüsün Avrupa kıtasında görülmeye başladığı 2020 yılının ilk aylarından itibaren dünya genelinde halk sağlığının büyük bir tehdit altına girdiği görülmüştür. Bunun bir sonucu olarak virüsün yayılma hızını engellemek adına alınan önlemler ve yaşanan sosyal izolasyon süreciyle birlikte insanlar vakitlerinin neredeyse tamamını evlerinde geçirmeye başlamışlardır. Şirketler evden çalışma sistemine geçmiş, dünya genelinde çevrimiçi eğitim dönemi başlamış, alışveriş merkezleri kapatılmış, sinema, tiyatro ve sportif etkinlikler yapılamamıştır.

Bu kriz döneminden etkilenen sektörler arasında spor endüstrisi de yer almaktadır. Birçok spor organizasyonu tamamen iptal edilmiş, bir bölümü ise ara vermek zorunda kalmıştır. Normalleşme sürecinin ilk adımında stadyumlara seyirci alınmamış ikinci adımında ise farklı ülke standartlarına göre belirli sayıda seyirci alınmıştır. Bunun bir sonucu olarak spor organizasyonları, kitlelerine ulaşabilmek için yeni yollar bulma arayışına girmişledir. 
$\mathrm{Bu}$ çalışmanın temel amacı spor organizasyonlarının Covid-19 salgını sürecinde yaşanan kriz döneminde esporu nasıl kullandıklarını ve kriz yönetiminin bir parçası olarak nasıl ele aldıklarını ortaya koymaktır. Covid-19 salgını gibi toplumu büyük bir ölçüde etkileyen bir olay karşısında spor organizasyonlarının esporu ele alış biçimlerinin incelenmesi bu çalışmayı önemli kılmaktadır.

\section{Covid-19 Pandemisinin Spor Üzerindeki Etkisi ve Sporda Kriz Yönetimi}

Küresel anlamda başta sağlık sektörü olmak üzere eğitim, sanayi, ulaşım, turizm ve spor gibi birçok sektörü etkileyen COVID-19 pandemisinin ekonomik, sosyal, ticari alanda etkisinin olduğu, söz konusu spor olduğunda ise bu etkinin ekonomik, kültürel, ticari vb. birçok farklı şekilde ortaya çıktığı görülmektedir. Tüm dünyayı etkisi altına alan Covid-19 pandemisinden diğer birçok sektördeki etkinlikler gibi sportif faaliyetler de büyük ölçüde etkilenmiş, birçok önemli spor organizasyonu ertelenmek ya da tamamen iptal edilmek zorunda kalmıştır. Güncel bir araştırmaya göre; 2020 yılı içerisinde yapılması planlanan etkinliklerin sadece \%53’ünün gerçekleştirilmesi beklenmektedir (Cutler, 2020). Aynı zamanda yaşanan bu zorlu sürecin neticesinde sporun tüm bileşenleri ekonomik, fiziksel ve psikolojik anlamda etkilenmiş ve genel itibarıyla modern sporlar, II. Dünya Savaşı'ndan bu yana ilk defa bu kadar uzun süreli bir kesintiye uğramıştır. Bu durum beraberinde önemli krizleri getirmiştir.

Kriz kavramı en genel haliyle "organizasyonu, şirketi veya sektörü ve bunun yanı sıra takipçilerini, ürünlerini, hizmetlerini veya adını etkileyen potansiyel olarak olumsuz bir sonucu olan büyük bir olaydır (Fearn-Banks, 2010: 2)” şeklinde tanımlanabilirken, işletme içi (örgütün işleyişi, yönetim şekli, örgütteki insan kaynağının özellikleri ve kültürel yapısı vb.) ya da işletme dışı (doğal şartların, toplumsal, ekonomik, teknolojik ve politik yapının değişmesi gibi çevresel faktörler) etkenlerin krizlere neden olabildiği belirtilmiştir (Öztamur, 2019: 6).

Birçok alanın çalışma konusu olan "kriz" kavramı ile ilgili olarak literatürde çok fazla tanım bulunmaktadır. Fransızca kökenli olan kriz kelimesi ekonomik anlamda “çöküntü”, mecaz olarak ise "Bir ülkede veya ülkeler arasında, toplumun veya bir kuruluşun yaşamında görülen güç dönem, bunalım, buhran” anlamına gelmektedir (TDK, 2020). Coombs (1999: 2) kriz kavramını "yanlış ele alınması halinde organizasyon, endüstri veya paydaşlar üzerinde olumsuz etkisi olabilecek öngörülemeyen, büyük bir tehdit olan bir olay" şeklinde açılamaktadır.

Kriz kavramının belki de en yakın olduğu alanları spor organizasyonları oluşturmaktadır. Çünkü spor etkinliklerinde organizasyon, sporcu ve seyircilerin eş zamanlı olarak yönetilmesi gerekmektedir. Bu konuda Miles ve Shipway (2020), kriz ve afet yönetimi alanındaki geçmiş ve şimdiki çalışmaların kapsam incelemesine dayanarak uluslararası spor etkinlikleri için değerlendirme çerçevesi oluşturmuştur (Şekil 1). Bu düşünceyle 
kriz ve afet yönetimi çerçevesi detaylı bir şekilde incelendiğinde üç ana faktör ortaya çıkmaktadır. Bu faktörler ekonomik, sosyal ve psikolojik etkiler olarak spor endüstrisinde etkisini gösteren bir kriz durumunda ortaya çıkmaktadır.

\section{Şekil 1. Uluslararası Spor Etkinlikleri Ve Mekanlarında Kriz ve Afet Yönetimini Anlamak İçin Bir Çerçeve}

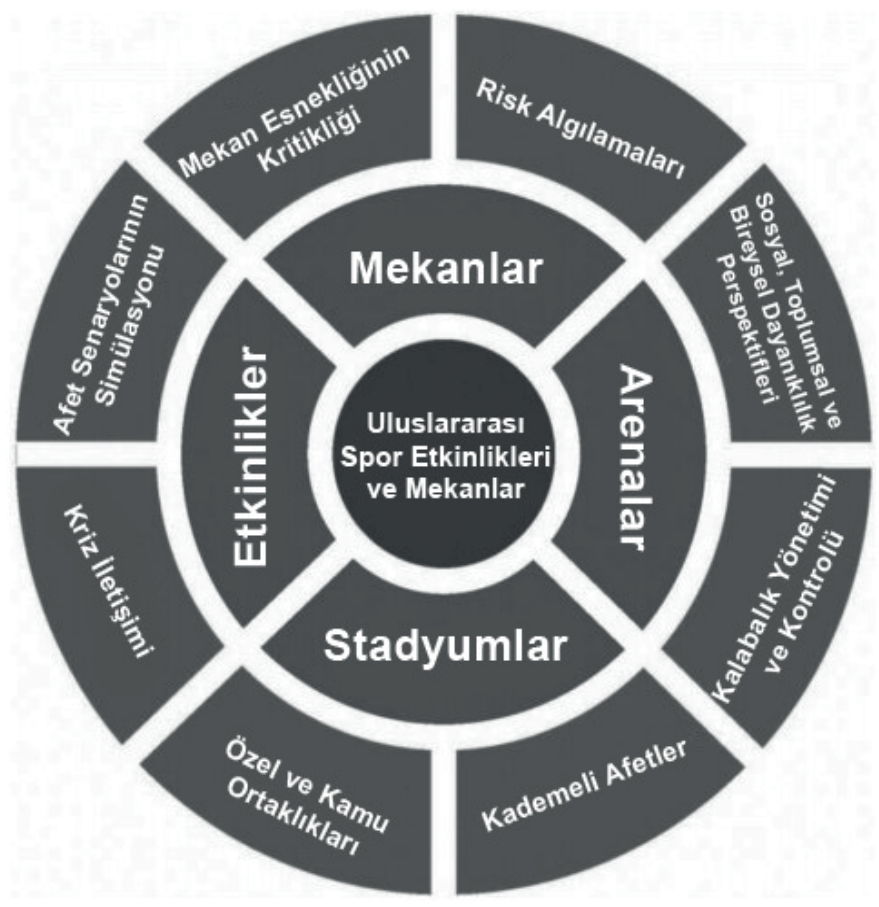

Covid-19 salgınıyla spor alanında etkisi görülen en büyük kriz, 24 Temmuz - 9 Ağustos 2020 tarihleri arasında gerçekleştirilmesi planlanan Tokyo 2020 Yaz Olimpiyatlarının, 23 Temmuz - 8 Ağustos 2021 tarihinde gerçekleştirilmek üzere ertelenmiş olmasıdır. Tarihte I. Dünya Savaşı nedeniyle 1916 yılında ve II. Dünya Savaşı nedeniyle 1940 ve 1944 yıllarında olmak üzere 3 kez gerçekleştirilemeyen Yaz Olimpiyatları ilk kez ertelenmek zorunda kalmıştır. Kansai Üniversitesi ekonomi profesörü Miyamoto'ya göre (2020) 30 milyar dolara mal olması beklenen Tokyo Olimpiyatları için alınan bu erteleme kararıyla birlikte 5,7 milyar dolarlık bir zarar (Stadyum ve olimpiyat köyü bakım maliyeti, halkla ilişkiler harcamaları, lojistik süreç vb.) oluşması beklenmektedir. Ayrıca oyunlar için 2020 yazında şehre gelmesi beklenen turistler nedeniyle hedeflenen gelirlere de ulaşılamayacağı belirtilmiştir. Bu noktada spor organizasyonlarının bu kriz dönemlerini en az hasarla atlatmak adına ani manevralar yaparak yönetim politikalarını, faaliyetlerini ve iletişim çalışmalarını güncelledikleri görülmektedir. Kriz dönemleri organizasyonların yönetim süreçlerine de önemli ölçüde etki etmektedir. 
Spor, tarih boyunca insan yaşamında her dönem önemli bir yere sahip olmuştur. İnsanlık sporu; taşıyıcı - toplayıcı dönemde vücudu en iyi durumda tutmak, yerleşik hayata geçildiğinde insan gücünü değerlendirmek ve yoğun savaş dönemlerinde askeri ihtiyaç için araç olarak kullanmıştır. Spor modern insanın hayatında ise birden çok işlevi yerine getirir. Bu konuda Çakır (2014:1) modern insanın gündelik hayatında olağanüstü merkezi bir konum edinen sporun, aynı zamanda günümüzün en güçlü sosyal olgularından birisi olarak kabul edildiğinden ve toplumsal yaşamdaki yerini giderek artırdığından bahsetmiştir. Bu kapsamda sporun kitlelere yayılması için spor organizasyonlarına ihtiyaç duyulmaktadır. Spor organizasyonlarının genel çevresinin ise; ekonomik, politik, demografik, sosyokültürel, yasal, ekolojik, teknolojik faktörlerden oluştuğu belirtilmiştir (Ekmekçi, 2016: 25). Bu nedenle toplumsal bir olgu olan ve hemen hemen birçok sektör ile iç içe geçmiş olan spor endüstrisi, dünya üzerinde meydana gelen olaylardan önemli ölçüde etkilenmektedir. Günümüz küresel dünyasında meydana gelen doğal afet, ekonomik kriz vb. tüm olaylar spor endüstrisi üzerinde iz birakmaktadır.

Spor endüstrisinde ortaya çıkan bir diğer büyük kriz; 12 Haziran - 12 Temmuz 2020 tarihleri arasında gerçekleştirilmesi planlanan 2020 Avrupa Futbol Şampiyonası'nın 17 Mart 2020 tarihinde alınan kararla birlikte bir yıl ertelenmiş olmasıdır. Organizasyonun 11 Haziran - 11 Temmuz 2021 tarihlerinde yine 2020 Avrupa Futbol Şampiyonası adıyla gerçekleştirilmesine karar verilmiştir (UEFA, 2020). UEFA tarafından alınan bu kritik kararın ekonomik anlamda 300 milyon Euro civarında bir zarara neden olması, eğer organizasyon gelecek yıl da gerçekleştirilemez ve iptal edilirse bu zararın 400 milyon Euroyu aşması beklenmektedir (Lange, 2020).

Avrupa Futbol Şampiyonası örneğinde de olduğu gibi Covid-19 salgının spora etkisi açık bir şekilde görülmekte ve yönetilmesi gereken kriz durumlarını ortaya çıkarmaktadır. Kriz yönetimi konusunda Demirtaş (2000: 363) “olası kriz durumuna karşılık, kriz sinyallerinin alınarak, değerlendirilmesi ve örgütün kriz durumunu en az kayıpla atlatabilmesi için gerekli önlemlerin alınması ve uygulanması sürecidir." tanımını yapmıştır. Bu tanıma ek olarak kriz yönetiminin; bir krizin olumsuz sonuçlarını önlemeyi veya azaltmayı ve böylece organizasyonu ve paydaşları zarardan korumayı amaçladığı ve birbiriyle ilişkili dört faktörden (önleme, hazırlık, müdahale ve revizyon) oluştuğu belirtilmiştir (Coombs, 2014: 21).

Covid-19 salgının oluşturduğu spor krizinin Türkiye'deki etkisi ise ilk vakanın ortaya çıktığı 10 Mart 2020 tarihinden itibaren 2019-2020 sezonu için spor müsabakalarının iptal olması veya seyircisiz olarak devam etmesi şeklinde görülmüştür. Basketbol, voleybol ve hentbol gibi branşlarda federasyonlar sezonu sonlandırma kararı alırken, futbolda 19 Mart 2020 tarihinde ara verilen Süper Lig karşılaşmaları 12 Haziran 2020 tarihinde yeniden başlamıştır. 
Yaklaşık olarakverilen üç aylık arada özellikle maç günü gelirleri anlamında büyük kayıplar meydana gelmiş, normalleşme sürecinde karşılaşmaların seyircisiz oynanması nedeniyle bu kayıpların büyük ölçüde devam ettiği görülmüştür. Türkiye Futbol Federasyonu'nun 2019 - 2020 sezonunun kalan bölümünün seyircisiz oynanacağını açıklamasıyla birlikte maç günü gelirleri anlamında 100 milyon TL'lik bir kaybın oluşması öngörülmektedir (Aktifbank, 2020). Köln Spor Üniversitesi'nden Profesör Christoph Breuer (2020) ortaya çıkacak durumla ilgili olarak "İzleyici geliri, profesyonel sporlar için merkezi bir gelir kaynağıdır. Bunlar artık yok oluyor. Diğer gelir kaynakları, sponsorluk ve medya gelirleri de risk altındadır, çünkü sözleşmeye bağlı olarak kabul edilen hizmetler sağlanamamaktadır" ifadelerini kullanmaktadır. Görüldüğü gibi spor endüstrisi, toplumun oldukça geniş bir bölümünü etkileyen bir sektördür. Gerçekten, bu sektör bir bütün olarak toplumla birlikte giderek daha karmaşık bir durum oluşturmaktadır. Shipway, Miles ve Gordon (2021) hangi krizlerin, acil durumların ve felaketlerin büyük spor olaylarını etkileyeceğini ve bunların nasıl yönetileceğinin öngörülemez hale geldiğini açıklamıştır.

Kriz ile ilgili yapılan tanımlarda krizin "Bir olay mı?” yoksa "Bir süreç mi?" olduğu üzerine anlaşmazlıklar vardır. Ancak kriz yönetimi, olası katkılardan veya kamu politikası sürecine katılımdan daha çok itibarın korunmasıyla ilgilendiği belirtilmiştir (Jacques, 2009). Bu durumun en net örneklerinden biri Avrupa futbol liglerinin arasında görülmüştür. UEFA tarafından ülke katsayılarına göre yapılan sıralamada ilk 10 sırayı oluşturan ülkelerin aldığı kararlara bakılacak olursa itibarlarını korumak amacıyla en hızlı şekilde harekete geçtikleri ve sürece göre güncellemeler yaptıkları görülmektedir. Fransa, Hollanda ve Belçika'da 2019- 2020 sezonu sonlandırılırken, diğer 7 ülkede ligler normalleşme süreci kapsamında alınan kararlarla birlikte yeniden başlamıştır (Tablo $1^{1}$ ).

Tablo 1. UEFA Ülke Katsayıları Sıralamasında ìlk 10'da Yer Alan Ülkelerin Covid-19 Salgınına Yönelik Olarak Aldığı Kararlar

\begin{tabular}{|c|c|c|c|c|c|}
\hline Lig & Ülke & $\begin{array}{l}\text { Ertelenme } \\
\text { Tarihi }\end{array}$ & $\begin{array}{c}\text { Yeniden } \\
\text { Başlama } \\
\text { Tarihi }\end{array}$ & $\begin{array}{l}\text { Sona } \\
\text { Erme } \\
\text { Tarihi }\end{array}$ & Karar \\
\hline La Liga & İspanya & 12.03 .2020 & 11.06 .2020 & 19.07.2020 & $\begin{array}{l}\text { Lig kaldığı yerden } \\
\text { devam ederek } \\
\text { tamamlandı. }\end{array}$ \\
\hline $\begin{array}{l}\text { Premier } \\
\text { League }\end{array}$ & İngiltere & 13.03 .2020 & 17.06 .2020 & 26.07.2020 & $\begin{array}{l}\text { Lig kaldığı yerden } \\
\text { devam ederek } \\
\text { tamamlandı. }\end{array}$ \\
\hline Bundesliga & Almanya & 13.03 .2020 & 16.05 .2020 & 27.06 .2020 & $\begin{array}{l}\text { Lig kaldığı yerden } \\
\text { devam ederek } \\
\text { tamamlandı. }\end{array}$ \\
\hline
\end{tabular}

1 Bu tablo ilgili ülke ligleri ya da federasyonlarının resmi web sitelerinde yapılan duyurular incelenerek oluşturulmuştur. 


\begin{tabular}{|c|c|c|c|c|c|}
\hline Serie A & İtalya & 09.03 .2020 & 20.06 .2020 & 02.08 .2020 & $\begin{array}{l}\text { Lig kaldığı yerden } \\
\text { devam ederek } \\
\text { tamamlandı. }\end{array}$ \\
\hline Ligue 1 & Fransa & 13.03 .2020 & - & 28.04 .2020 & $\begin{array}{l}\text { Lig sonlandırıldı } \\
\text { ve kararın alındığı } \\
\text { tarihte lider olan } \\
\text { takım şampiyon ilan } \\
\text { edildi. }\end{array}$ \\
\hline Primeira Liga & Portekiz & 12.03 .2020 & 03.06 .2020 & 26.07.2020 & $\begin{array}{l}\text { Lig kaldığı yerden } \\
\text { devam ederek } \\
\text { tamamlandı. }\end{array}$ \\
\hline $\begin{array}{l}\text { Premier } \\
\text { League }\end{array}$ & Rusya & 17.03.2020 & 19.06 .2020 & 22.07 .2020 & $\begin{array}{l}\text { Lig kaldığı yerden } \\
\text { devam ederek } \\
\text { tamamlandı. }\end{array}$ \\
\hline Pro League & Belçika & 13.03 .2020 & - & 15.05 .2020 & $\begin{array}{l}\text { Lig sonlandırıldı } \\
\text { ve kararın alındığı } \\
\text { tarihte lider olan } \\
\text { takım şampiyon ilan } \\
\text { edildi. }\end{array}$ \\
\hline $\begin{array}{l}\text { Premier } \\
\text { League }\end{array}$ & Ukrayna & 17.03 .2020 & 30.05 .2020 & 19.07.2020 & $\begin{array}{l}\text { Lig kaldığı yerden } \\
\text { devam ederek } \\
\text { tamamlandı. }\end{array}$ \\
\hline Eredivisie & Hollanda & 12.03 .2020 & - & 24.04 .2020 & $\begin{array}{l}2019 \text { - } 2020 \text { sezonu } \\
\text { iptal edildi. }\end{array}$ \\
\hline
\end{tabular}

Avrupa'daki bir diğer popüler spor branşı olan basketbolun en önemli iki organizasyonu olan EuroLeague ve Eurocup'ta 2019 - 2020 sezonu 25 Mayıs 2020 tarihinde alınan kararla iptal edilmiştir (Euroleague, 2020). Pandeminin Avrupa'da yayılmaya başladığı 12 Mart 2020 tarihinde karşılaşmalara ara veren Euroleague yönetimi sporcu, seyirci, personel, paydaşlar ve topluluk sağlığının öncelikleri olduğunu belirterek sezonu sonlandırdı. EuroLeague Basketball Başkanı Jordi Bertomeu iptal kararının büyük bir ekonomik etkisi olacağını söylerken, takımlarla olan anlaşmaları yeniden gözden geçirdiklerini ve bu etkiyi en aza indirmek için çalıştıklarını belirtmektedir (Dixon, 2020). EuroLeague Basketball Başkanı Jordi Bertomeu'nun açıkladığı iptal kararıyla EuroLeague yönetimi Covid-19 salgının oluşturduğu krizin çözümüne geleneksel yaklaşım modeli uygulamıştır. Geleneksel yaklaşım ise Claeys ve Opgenhaffen (2016) tarafından, halkın kritik bir konunun farkına varacağını ve ardından kuruluşun kriz tepkisinin eyleme geçirileceğini varsayan “Gök gürültüsü” nün gelmesini beklemek olarak tanımlanmıştır. Bu nedenle zamanlama, uygulayıcıların sorunun krize dönüştüğü bir sonlandırma noktası başlatma kararına 
bağlıdır. Sorunlar tanımlanmış ve kriz yönetimi uygulamaya hazırsa, "gök gürültüsü" metaforunun itibarı korumak hatta geliştirmek için kullanılabileceğini belirtilmektedir (Kitchin ve Percell, 2017).

Amerikan Basketbol Birliği NBA'de ise 11 Mart 2020 tarihinde bir oyuncunun Covid-19 testinin pozitif çıkması sonucunda karşılaşmalar ertelenmiş, 4 Haziran 2020'de ise ligin farklı bir formatla 31 Temmuz 2020 tarihinde yeniden başlayacağı açıklanarak sezonun tamamlanmasına karar verilmiştir. Yeniden planlanan ve farklı bir formatta oynanan karşılaşmalarda seyirci olmaması nedeniyle Los Angeles Lakers'ın bilet gelirlerinden yaşadığı kaybın 82 milyon doları bulması beklenmektedir (Statista, 2020).

Maç günü gelirlerinin ortadan kalkması, sponsorların zarar görmesi vb. temel etkilerin yanı sıra salgınının ne zaman kesin bir şekilde sonlanacağının bilinmemesi nedeniyle spor dünyasında oluşan ekonomik sarsıntının sürmesi beklenmektedir. Benzer bir durum 2008 ekonomik krizi sonrası ortaya çıkmıştır. Bu durum mali kısıtlama ve kamu finansmanında önemli değişiklikler oluşturmuş böylelikle birçok Avrupa spor organizasyonu sınırlı kaynaklar ve kısıtlı zaman içinde başarının sağlanmasıyla ilgili yüksek kaliteli hizmetler sunma konusunda stres yaşayacağı düşünülmektedir (Kerwin, 2016). Spor dünyasında oluşan bu büyük ölçekteki etkilerin yanı sıra mikro etkiler de söz konusudur. Spor ile doğrudan ya da dolaylı olarak ilgili işlerde çalışan birçok insan bu süreçten etkilenmiştir. ABD'de yapılan bir araştırmaya göre; Covid-19 salgını nedeniyle toplamda spor ile ilgili 1,3 milyon iş tehlike altındadır ve en fazla etkilenen iş grupları arasında antrenörler, gözlemciler (scout), fitness eğitmenleri, cankurtaranlar, eğlence ve rekreasyon görevlilerinin yer aldığı belirtilmiştir (Burrow, 2020).

Bir krizde paydaşlara zarar gelmesi en önemli “olumsuz sonuç” olarak değerlendirilirken, bu zararların fiziksel, finansal ve psikolojik olmak üzere her türlü zararı kapsadığı belirtilmektedir (Coombs, 2010: 19). Covid-19 salgınının ekonomik etkilerinin yanı sıra sporcular üzerindeki fiziksel ve psikolojik etkileri de dikkat çekmektedir. Salgın süresince tüm dünyada yapılan uyarılar ve uygulanan kısitlamalar nedeniyle sporcuların antrenman şartlarına da mecburi sınırlamalar gelmiştir. Beklenmeyen ve ani bir şekilde ortaya çıkan salgın neticesinde oluşan bu sınırlamaların sporcuların fiziksel durumu üzerinde ilerleyen dönemlerde olumsuz etkileri olması tahmin edilmektedir. Antrenman rutinleri bozulan ve alışkanlıkları değişen sporcuların bu sürecin ardından yeniden eski formlarına kavuşması zaman alacaktır.

Karantinalar, hastalığı önleme ve azaltmanın gerekli bir parçası olmakla birlikte, etkilenenlerin ruh sağlığı üzerinde ciddi ve uzun süreli etkilere sahiptir (Imam, Javeed ve Kennedy, 2020: 132). Fransız Spor Psikoloğu Chamalidis (2020) ise Covid-19 salgını nedeniyle verilen aranın sporcular üzerindeki etkisini şu şekilde açlklıyor; "Sporun sert bir şekilde durması, sporcuların geriye gitmesine ve bunalmasina neden olabilir. Bu sporda ciddi bir 
sorundur. Asıl sorun hedeflerin olmaması. Birkaç ay sürebilen bir sakatlık nedeniyle ani bir durmanın aksine, tüm spor gündemi durdu, bu nedenle sporcuların odaklanacağı hiçbir şey yok." Castillo (2020) ise sporcuların içinde bulunduğu psikolojik durum ile ilgili olarak "Sosyal alarm, ertelenen yarışmaların belirsizliği, Olimpiyat Oyunlarının ertelenmesi ve bu insanların akıllarını yıllardır bu hedeflere koyduklarını düşünürsek, sonuç stres veya endişeye neden olabilecek bir duygu yığınıdır" demektedir.

Aynı zamanda profesyonel ve amatör birçok faaliyetin iptal edilmesinin, hem sporcuların hem de çalışanların psikolojisi üzerinde önemli izler bırakması beklenmektedir. Psikolog Stark (2020) özellikle alt yaş gruplarındaki sporcuların bu durumdan fazlasıyla etkilendiğini belirtirken "Çocuklarımızın çoğu daha önce böyle zor bir dönem yaşamadı. Bu nedenle en çok onlar etkileniyor. Lise hayatınızda en önemli şeylerin ne olduğunu düşünecek olursanız aklınıza ilk gelenler genelde son sinıftaki sportif faaliyetler, mezuniyet baloları olacaktır. Bu anıları yaşayamayacak olmak onları üzüyor. Bu tip özel anların çocukların benlik saygısı ve özgüveni üzerinde önemli etkileri vardır” ifadelerini kullanıyor.

Tüm bunların yanında bu süreçte 18 yaş altındaki bireyler için uygulanan kısıtlamalar göz önüne alındığında en çok etkilenen kesimin başında altyapı sporları gelmektedir. ABD'de yapılan ve 290 altyapı programı yöneticisinin katıldığı bir araştırmada; programların \%46'sının kalıcı şekilde kapanma tehlikesi yaşadığı, sporcu ebeveynlerinin ise \%48'inin pandemi sonrasında kısa süre içerisinde çocuklarını yeniden bir spora kaydettirme olasılıklarının düşük olduğu belirtilmiştir (Silverman, 2020). Türkiye'de de benzer şekilde özellikle salonda gerçekleştirilen basketbol, voleybol gibi sporların akıbeti oldukça önemlidir. Bu branşlarda altyapı çalışmaları gerçekleştiren spor kulübü ve spor okulları bu süreç boyunca çalışmalarını gerçekleştiremedikleri için ekonomik olarak etkilenmekte, dolayısıyla yönetici, antrenör ve diğer paydaşlar da bu etkiye maruz kalmaktadır.

Covid-19 salgını ortaya çıktığı ilk günden bu yana bütün dünyayı etkisi altına almıştır. Salgının yayılmasını engellemek adına alınan sosyal mesafeli önlemler, sosyal yaşamın (okul, iş vb.) sınırlandırılması, spor da dâhil olmak üzere insan hayatındaki birçok düzenin bozulmasına neden olmuştur. Covid-19 salgınını sadece bir halk sağlığı krizi değil aynı zamanda modern tarihte eşi görülmemiş bir ekonomik kriz olarak da nitelendirilmektedir (Brands ve Gavin, 2020). Sporun toplumların ekonomik ve sosyal refahında önemli bir yeri olduğunu düşünecek olursak Covid-19’un spor üzerindeki tüm etkileri direkt olarak topluma da etki etmektedir.

\section{Kriz Döneminde Yeni Bir Firsat: Espor}

Covid-19 salgınının yoğun bir şekilde yaşandığı 2020 yılının mart, nisan ve mayıs aylarında spor organizasyonları tüm dünyada durma noktasına geldi. Covid-19 salgını kısa sürede gösterdiği etkiyle birlikte spor endüstrisin 21. yüzyılda karşılaştığı en önemli krizlerin arasındaki yerini aldı. Stratejik dönüm noktası olarak adlandırılan kriz kavramı, 
bir işletmenin temel direklerinin değiştiği an olarak ifade edilirken, bu durum işletmenin yükselmesi için bir fırsat ya da sonun başlangıcı anlamlarına geldiği belirtilmektedir (Grove, 1996).

Covid-19 salgınının yarattığı kriz döneminde seyir sporunun durmasıyla birlikte organizasyonlar, kitlelere sunmak üzere yeni bir içerik arayışına girmişlerdir. Bu dönemde kitleleriyle etkileşim kurmak isteyen spor organizasyonları tarafından medya içeriğine yönelik olarak dikkate değer iki yaklaşım (Mastromartino, Ross, Wear ve Naraine, 2020:

6) göze çarpmaktadır;

- Geçmiş maç tekrarları, önemli anlar veya röportajlar,

- Canlı espor etkinlikleri.

Dijital oyunlar ve esporların özellikle son yıllarda gösterdiği gelişim dikkat çekici noktaya ulaşmıştır. Küresel dijital oyun pazarının 2020 yılında 160 milyar dolara ve oyuncu sayısının ise 2,7 milyar kişiye ulaşması beklenirken (Newzoo, 2020), espor pazarının ise yaklaşık 1 milyar dolara ve espor izleyicisi sayısının 500 milyon kişiye ulaşacağı tahmin edilmektedir (Rietkerk, 2020). Bunun bir sonucu olarak spor organizasyonları, espor ile ilgili yatırımlar gerçekleştirmeye devam etmektedir ve Covid-19 pandemisi sırasında tüm dünyada spor etkinliklerinin durma noktasına gelmesiyle birlikte modern sporlar ile espor arasındaki etkileşim farklı bir noktaya gelmiştir.

$\mathrm{Bu}$ dönemde dünya genelinde uygulanan sokağa çıkma kısıtlamaları ile birlikte insanlar uzunca bir süre, zamanlarının neredeyse tamamını evlerinde geçirmiş ve eğlence amaçlı olarak gerçekleştirdikleri etkinlikler sınırlanmıştır. İnsanlar bu gibi afet ve kriz durumlarında zamanlarını değerlendirmek ve bu süreci en iyi şekilde atlatmak için çeşitli aktivitelere yönelmiştir. Günümüzde bu aktivitelerin gerçekleştirilmesinde dijital araçlar da kullanılmaktadır. Bu süreçte giderek gelişen dijital oyun endüstrisi daha fazla ilgi görmüştür.

Dijital oyunlarla olan etkileşim düzeyi tüm zamanların en yüksek seviyesine ulaşırken, Covid-19 pandemisi sırasında dijital oyunlara karşı olan ilgi ABD'de \%46, Fransa'da \%41, Birleşik Krallık’ta \%28 ve Almanya'da \%23 artış göstermiştir (Nielsen, 2020a). Nisan 2020'de yapılan bir araştırmada ise 35 yaş altındaki katılımcıların yarısından fazlasının dijital oyun ya da espor izlemeye açık olduğu sonucuna ulaşılırken (PwC, 2020), Mart 2020'de dijital oyunculuk odaklı yayın platformları olan Twitch'te \%10, Youtube Gaming'de ise \%15'lik bir izlenme artışı görüldüğü belirtilmektedir (Gough, 2020). Aynı zamanda Covid-19 salgınına bağlı olarak dijital oyun satışlarına yönelik ilginin arttığı görülmüştür. 16-22 Mart 2020 haftasında 4,3 milyon oyun satılmıştır. Bu, bir önceki haftaya göre \%63'lük bir artış anlamına gelmektedir (Dring, 2020). Avrupa İnteraktif Yazılım Federasyonu ISFE tarafından oynama süresi, eğitim, mental sağlık ve beraber oynama başlıkları altında 3000 katılımcı ile yapılan araştırmada dijital oyunların karantina sürecinde 
bireyler tarafından nasıl ele alındığı incelenmiştir (ISFE, 2020). Buna göre; 6-64 yaş aralığındaki oyuncular arasında oyun oynama sürelerinin bir önceki yıla oranla haftalık olarak ortalama 1,5 saat arttığı görülmektedir. Ayrıca her beş oyuncudan birinin dijital oyunları aileleriyle veya çevrimiçi ortamda arkadaşlarıyla oynadığı belirtilmiştir. Bu durum Covid-19 salgını döneminde dijital oyunlarla etkileşime giren kitlenin demografik anlamda genişlediğini göstermektedir.

Bu noktada dijital oyunlar, uygulanan kısıtlamalar nedeniyle evde olağandan daha fazla vakit geçiren insanlara ulaşmak için olanak sağlamaktadır. Tüm bunları göz önüne alacak olursak spor organizasyonlarının hem kitlelerin ilgisini aktif tutabilmek için yeni bir içerik elde etmek, hem de yeni bir yatırım alanı keşfetmek adına espor ile ilgili çalışmalar gerçekleştirdiği görülmektedir. Ayrıca bu dönemde hâlihazırda espora yatırım yapan organizasyonların yatırımlarını genişletme, ilk defa bu alana girecek olan organizasyonların ise kendilerini test etme fırsatını yakaladıkları gözlemlenmiştir (Tablo 2).

\section{Tablo 2. Covid-19 Salgını Sırasında Espor Etkinliği Düzenleyen Bazı Spor Organizasyonları}

\begin{tabular}{|c|c|c|c|}
\hline Spor Organizasyonu & Espor Etkinliği & Tarih & Oyun \\
\hline Türkiye Süper Lig & Türkiye EFutbol Turnuvası & 9 - 10 Mayıs 2020 & FIFA 2020 \\
\hline NBA & NBA 2K Players Tournament & 3 -12 Nisan 2020 & NBA $2 \mathrm{~K}$ \\
\hline İngiltere Premier Ligi & $\begin{array}{l}\text { ePremier League } \\
\text { Invitational }\end{array}$ & 21 - 25 Nisan 2020 & FIFA 2020 \\
\hline Formula 1 & Virtual Grand Prix & 22 Mart 2020 & Formula 1 \\
\hline Nascar & NASCAR iRacing Pro & 22 Mart 2020 & Nascar \\
\hline FIBA & FIBA Esports Open & 19 - 21 Haziran 2020 & NBA 2K \\
\hline $\begin{array}{c}\text { Finlandiya Buz } \\
\text { Hokeyi Ligi }\end{array}$ & ePlayoffs 2020 & 8 - 25 Nisan 2020 & EA NHL \\
\hline Almanya Bundesliga & Bundesliga Home Challenge & $\begin{array}{c}28 \text { Mart - } 19 \text { Nisan } \\
2020\end{array}$ & FIFA 2020 \\
\hline İspanya La Liga & LaLiga Santander Challenge & 20 - 22 Mart 2020 & FIFA 2020 \\
\hline İtalya Serie A & Everybody Plays Home & $24-28$ Mart 2020 & FIFA 2020 \\
\hline
\end{tabular}


2018 yllından bu yana profesyonel bir espor ligi bulunan NBA (2020), salgın sürecinde NBA'de forma giyen oyuncuların yarıştığı bir espor turnuvası organize etmiştir (Şekil 2). Organizasyon sonunda yarışmayı kazanan Phoenix Suns sporcusu Devin Booker adına koronavirüs yardım çabalarını desteklemek için 100.000 dolar tutarında bağışta bulunulmuştur.

\section{Şekil 2: NBA Resmi Twitter Hesabının Paylaşımı}

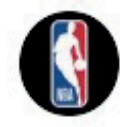

NBA@@NBA.12 Nis

Congrats to @DevinBook on becoming the first-ever NBA 2K Players Tournament Champion! 2K, the NBA and NBPA are all contributing a $\$ 100,000$ donation in Devin's name to Direct Relief and Arizona Food Bank Network in support of ongoing coronavirus relief efforts. \#NBA2KTourney

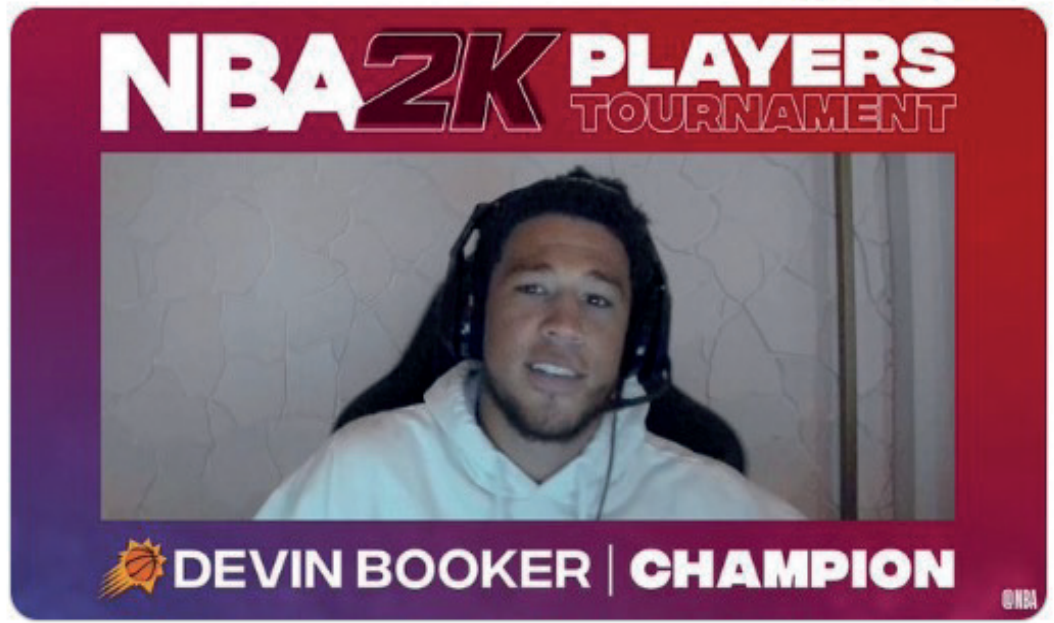

İngiltere Premier Ligi'nin de pandemi nedeniyle verilen bu arada espor yatırımlarına bir yenisini eklediği görülmektedir. 2019 yllından bu yana "ePremier League" adıyla bir espor ligi bulunan İngiltere Premier Ligi, pandemi döneminde futbol ylldızlarının dahil olduğu "ePremier League Invitational" turnuvasını gerçekleştirmiştir. Nisan ayında gerçekleşen ilk turnuvayı şampiyon olarak tamamlayan ve o dönem Wolverhampton Wanderers forması giyen Portekizli futbolcu Diego Jota organizasyonun sağladığı faydayı "İyi bir nedenden dolayı bir arada olduğumu, hayranların da dâhil olduğu iyi bir turnuva oldu. Şu anda, topluluklara yardım etmenin yollarını bulmalıyız ve ayrıca hayranları eğlendirmeye çalışmalıyız. Onlara evde oldukları zaman izleyecekleri bir şey vermeliyiz." ifadeleriyle açıklamaktadır (premierleague.com, 2020). İspanya futbolunun en üst düzey ligi La Liga'nın da bu dönemde bir espor etkinliği düzenlediği görülmektedir. La Liga'da bulunan 20 kulüpten 18 futbolcunun katılımıyla gerçekleşen organizasyon 20-22 Mart 2020 tarihleri arasında gerçekleştirildi. Televizyonda da yayınlanan etkinlik 205.000'den 
fazla kişi tarafından izlenirken, sosyal medyada 200.000'den fazla etkileşim elde ettiği görüldü (Nielsen, 2020b).

2017 yllından bu yana espor etkinliği gerçekleştiren Formula 1, Covid-19 pandemisi sürecinde bu alandaki çalışmalarına bir yenisini daha eklemiştir. "Virtual Grand Prix" adıyla gerçekleştirilen espor etkinliğine profesyonel Formula 1 sürücülerinin yanı sıra farklı spor branşlarından dünyaca ünlü sporcular katılırken, bu etkinlik toplamda 85 milyona yakın bir izlenmeye ulaşmış, sosyal medyada platformlarında ise yaklaşık 700 milyonluk bir etkileşim oranı elde etmiştir (f1esports.com, 2020). Kuzey Amerika'ya özgü motor sporlarından biri olan NASCAR tarafından 22 Mart 2020 Pazar günü gerçek NASCAR sürücülerinin sanal ortamda yarıştığı ilk "eNASCAR iRacing Pro Invitational Series" yarışması düzenlendi. NASCAR, Fox Sports 1 kanalından yayınlanan etkinlik sayesinde 2020 yılında henüz NASCAR Serisi izlememiş 255 bin yeni izleyiciye ulaşma şansı yakalarken, etkinliğin Twitter'da 217,300 etkileşim, 912,500 video görüntülemesi elde ettiği açıklandı (nielsen.com, 2020c). Covid-19 pandemisi nedeniyle sezonu iptal etme kararı alan Finlandiya Buz Hokeyi Ligi, gelen geri bildirimlerin ardından seyircilere bir içerik sunabilmek adına sezonun gayri resmi şampiyonunu espor ligi aracılığıyla belirleme kararı aldı (Forbes, 2020).

Türkiye'de 2018 yılında Gençlik ve Spor Bakanlığı onayıyla kurulan Türkiye E-Spor Federasyonu'nun pandemi sürecinde ödüllü “Evde Kal Kupası” turnuvaları düzenleyerek espora katılımı teşvik edici adımlar attığı görülmektedir. Futbolda ise Kulüpler Birliği Vakfı tarafından 9-10 Mayıs 2020 tarihlerinde düzenlenen Türkiye EFutbol Turnuvası, Süper Lig'de bulunan 18 takımdan birer oyuncunun katılımıyla gerçekleştirilmiştir (Şekil 3). Bu etkinlik aynı zamanda Kulüpler Birliği Vakfı (2020) tarafından gerçekleştirilen ilk resmi espor organizasyonu olma özelliğini taşımaktadır (Şekil 3).

Şekil 3: Kulüpler Birliği Vakfı'nın Türkiye EFutbol Turnuvası Paylaşımı

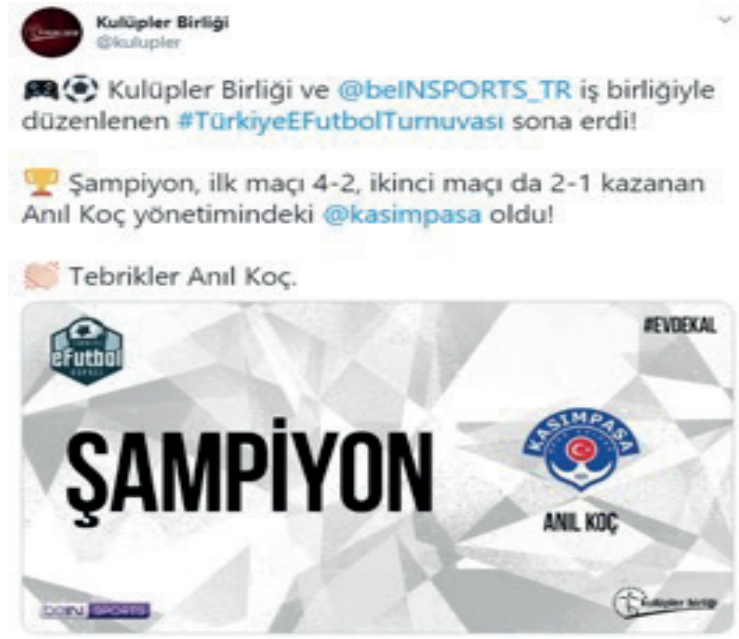


Pandemi sürecinde espor ile ilgili çalışmalar gerçekleştiren bir diğer organizasyon ise Uluslararası Basketbol Federasyonları Birliği FIBA'dır. FIBA tarafından 19 - 21 Haziran 2020 tarihleri arasında "FIBA Esports Open 2020" ismiyle ve 17 ülkenin katılımıyla gerçekleştirilen organizasyon FIBA'nın espor alanındaki ilk resmi organizasyonu olması nedeniyle önemli görülmektedir. Bu etkinlik FIBA'nın ve ulusal federasyonların resmi sosyal medya hesapları üzerinden yapılan yayınlarla birlikte 5 milyondan fazla görüntülenmeye ulaşmıştır. FIBA Genel Sekreteri Andreas Zagklis etkinlik ile ilgili olarak "Bu büyük bir başarıydı ve çok eğlenceliydi. Gelecekte daha fazla FIBA espor yarışmasının gerçekleşme olasılığı konusunda heyecan duyuyoruz. FIBA Merkez Kurulu, bu espor girişimini FIBA ailesini büyütmek için stratejik hedefle alakalı ve tutarlı buluyor. Bu etkinlik basketbolun tanıtımı için harikaydı." ifadelerini kullanmaktadır (FIBA, 2020).

\section{Sonuç}

Tüm dünyayı etkisi altına alan Covid-19 pandemisi sırasında spor endüstrisi kendisini büyük bir çıkmazın içerisinde bulmuştur. Spor endüstrisi her zaman büyük krizlerle başa çıkmak zorunda kalmıştır. Modern sporların 100 yılı aşkın tarihi boyunca yaşanan birçok siyasal, toplumsal, çevresel ya da ekonomik olay, spor üzerinde de etkili olmuştur. Toplumlar arasında savaşların meydana gelmesi, siyasal propagandalara neden olması, sporcuların ekonomik sosyal statüleri gereği örgütlenmesi (grev, lokavt), olumsuz çevresel faktörler (hava şartları, deprem, sel, yangın vb.), salgın hastalıklar, terörist saldırılar, kitle iletişim araçlarında meydana gelen aksaklıklar, ulaşım ve konaklama problemleri, iletişimde yaşanan dil problemleri, ekonomik ve finansal problemle gibi birçok neden spor kurumlarını ve organizasyonlarını etkilediği gibi sporun kendisi de bazen bu olumsuzluklara yol açmaktadır (Devecioğlu, 2003: 6). Fakat II. Dünya Savaşı'ndan bu yana ilk kez spor etkinlikleri bu denli durma noktasına gelmiştir. Spor etkinliklerinin neredeyse tamamının kısa ya da uzun süreli olarak durmasıyla birlikte spor organizasyonları sahip oldukları kitleleri aktif tutmak için arayış içerisine girmişlerdir.

Spor organizasyonlarının dijital oyunlar ile olan etkileşimi uzun bir geçmişe sahiptir. Bu etkileşim son yıllarda espor etkinlikleri ile birlikte farklı bir boyuta ulaşmıştır. Dünya çapında birçok spor kulübü kendilerine ait espor takımları oluşturmuş, birçok spor ligi kendi espor liglerini kurmuşlardır. Covid-19 pandemisi, spor organizasyonlarının espor ile olan etkileşiminde yeni bir dönemin başlangıcı olarak görülebilir. Bu süreçte alınan önlemler dâhilinde dünya genelinde insanlar izole olmak adına uzun süre vakitlerinin büyük bölümünü evlerinde geçirmişlerdir. Toplumun günlük hayatında büyük yer tutan sinema, tiyatro, konser vb. birçok etkinlik gerçekleştirilememiş, bu da doğal olarak insanların eğlence ve serbest zaman geçirme anlayışlarında normalin aksine değişikliklere neden olmuştur. İnsanların dijital oyunlar ile olan etkileşimi katlanarak artmıştır. 
$\mathrm{Bu}$ nedenle spor organizasyonlarının kitlelere ulaşmak ve onlarla aralarındaki bağı aktif tutabilmek için espor etkinliklerini devreye soktukları görülmektedir. Birçok spor organizasyonu, spor ligi ya da spor takımı var olan espor yatırımlarına yenilerini eklemiş, birçoğu ise ilk kez espor sahnesine çlkmıştır. Espor, pandemi sürecinde ortaya çıkan krizin aşılmasının yanı sıra organizasyonlara hem var olan kitlelerine hem de potansiyel kitlelere ulaşmaları için yeni bir içerik sağlamıştır. Modern sporlar ile espor arasında Covid-19 salgını sırasında artan etkileşimin ilerleyen dönemlerde de artarak devam edeceği düşünülmektedir. Foley (2020) araştırma şirketi tarafından yaşları 20 ile 50 arasında değişen 255 profesyonel yöneticiyle yapılan araştırmada; profesyonel spor endüstrisinin Covid-19 salgını sonrasında da dijital teknolojilere odaklanmaya devam edeceği sonucuna ulaşılmıştır. Katılımcıların \%49'u bu odaklanmanın espor ligleri, \%54’ü ise kendi sporlarının simülasyonları ile gerçekleştirecekleri turnuvalar aracılığıyla sağlanacağını belirtmektedir. Modern spor kulüplerinin espor ile etkileşime girmesindeki üç faktör olarak; esporun büyüyen bir ekonomiye sahip olması, potansiyel bir taraftar kitlesi barındırması ve farklı bir spor içeriği oluşturması gösterilmektedir (Üçüncüoğlu ve Çakır, 2017).

Sonuç olarak tüm dünyayı etkileyen Covid-19 salgınının oluşturduğu kriz döneminde spor organizasyonlarının hem büyüyen bir ekonominin içerisinde yer alma fırsatı yakaladığı hem de kitlelere ulaşmanın yeni yollarını keşfettiği görülmektedir. 


\title{
Use Of Esports As Part Of Crisis Management During The Covid-19 Pandemic
}

\author{
Mertkan Üçüncüoğlu* \\ Hamdi Özdemir** \\ Veli Ozan Çakır**
}

\section{Introduction}

The main purpose of this study is to reveal how sports organizations use esports during

the ongoing Covid-19 pandemic and how they handle it as a part of crisis management. Examining the ways in which sports organizations handle esports in the face of an society-shaking event such as the Covid-19 epidemic makes this study important. The Covid-19 pandemic is not only a public health crisis; it is an unprecedented economic crisis (Brands \& Gavin, 2020). Like the events in many other sectors, sporting activities have been greatly affected by the Covid-19 pandemic, causing many important sports organizations to postpone or cancel their activities completely. This situation brought important crises with it.

Generally, a crisis is defined as "a major event with a potentially negative consequence that affects the organization, company or sector as well as its followers, products, services or name" (Fearn-Banks, 2010: 2). One of the greatest crises in the field of sports during the Covid-19 pandemic is that the Tokyo 2020 Summer Olympics and the 2020 European Football Championship were postponed. Turkey's basketball, volleyball, and handball federations decided to end their seasons. By the way, in football, super League matches

* Ph.D. student, Istanbul University Cerrahpasa, Institute of Graduate Studies, Sports Management Sciences, Istanbul. mertkanucuncuoglu@gmail.com ORCID: 0000-0002-5589-2857

** Research Assistant, Istanbul University - Cerrahpasa, Faculty of Sports Sciences, Istanbul. hamdiozdemir@ istanbul.edu.tr ORCID: 0000-0001-7684-7898

** Assoc. Prof., Alaaddin Keykubat University, Faculty of Sports Sciences, Antalya, ozan.cakir@alanya.edu.tr ORCID: 0000-0001-7996-2138 
which were suspended on March 19, 2020, football was resumed on June 12, 2020. Match day revenue for the 2019-2020 season is expected to incur a loss of $\$ 100$ million after the Turkey Football Federation's decision to proceed with matches without hosting a live audience in stadiums (Aktifbank, 2020). According to Breuer (2020):

Audience income is a central source of income for professional sports. These are now breaking away. The other sources of income-sponsoring and media revenues-are also at risk because the contractually agreed service cannot be provided.

Whereas damage to stakeholders in a crisis is considered the most important negative consequence, these losses include all kinds of physical, financial, and psychological damages (Coombs, 2010: 19). The cancellation of many professional and amateur activities is expected to leave significant marks on the psychology of both athletes and employees. French Sports Psychologist Makis Chamalidis (2020) explains the effect of the break due to the Covid-19 outbreak on athletes as follows:

The brutal stop of sport in the athlete's life can lead them to be withdrawn or depressed. This is a serious problem in sports. The main problem is the lack of goals. As opposed to a brutal stop because of an injury, which can last a few months, the entire sports agenda has stopped. Therefore, the athletes have nothing to focus on.

With the cessation of fan sports events caused by the Covid-19 crisis, organizations started looking for new content to present to the masses. Two noteworthy approaches have emerged (Mastromartino, Ross, Wear, \& Naraine, 2020: 6) allowing sports organizations to interact with their fans through the media:

- Past match replays, highlights, and interviews

- Live esports events.

During the Covid-19 pandemic, the level of interaction with digital games reached an alltime high, while interest in digital games increased by $46 \%$ in the US, $41 \%$ in France, $28 \%$ in the UK, and 23\% in Germany during this period (Nielsen, 2020a). One study conducted in April 2020 concluded that more than half of the participants under the age of 35 were open to watching digital games or esports (PwC, 2020). In addition, in March 2020, viewership on eSports streaming platform Twitch and YouTube Gaming by 10 - 15 percent compared to the figures from the previous week. (Gough, 2020). While the global digital game market is expected to reach $\$ 160$ billion and the number of players 2.7 billion in 2020 (Newzoo, 2020), it is estimated that the esports market will reach approximately \$1 billion and the number of esports viewers will reach 500 million people (Rietkerk, 2020). During the Covid-19 pandemic, the interaction between modern sports and esports has 
undergone a transformation as sports events have come to a halt all over the world. Sports organizations are observed to be working on esports in order to create new content, and maintain the interest of fans, and discover a new investment area. While the Association of International Basketball Federations (FIBA) organized an esports event for the first time, many organizations that actively invest in esports (e.g., The Spanish La Liga, English Premier League, German Bundesliga, Formula 1, NASCAR, and NBA) have organized new esports events involving professional athletes during the pandemic. Turkey efootball tournament was organized by the Clubs Association Foundation on May 9-10, 2020, realized with the participation of one player from each of the 18 teams in the Super League. This event is also the first official esports event organized by the Clubs Association Foundation.

As a result, the sports industry found itself at an impasse during the worldwide Covid-19 pandemic. The sports industry has always had to deal with major crises. For more than 100 years, numerous political, social, environmental, and economic events throughout the history have influenced sports. The Covid-19 pandemic can be seen as the beginning of a new era in the interaction of sports organizations and esports. As a result of stay-athome mandates, people around the world have had to spend a large part of their time in their homes in either full or semi-isolation. Consequently, sports organizations have initiated esports activities in an effort to reach and maintain their bonds with fans. Many sports organizations, sports leagues, and sports teams have made new investments to their existing esports activities whereas many others have taken part in the esports scene for the first time. In addition to overcoming the emergent crisis, esports has facilitated the creation of new content able to reach both existing and potential fans.

\section{Kaynakça/References}

- Aktifbank (2020). Erişim Tarihi: 08.02.2021. https://www.aktifbank.com.tr/tr/aktifbankhakkinda/Basinodasi/bizden-haberler/Sayfalar/aktif-bank-covid-19-oncesi-ve-sonrasi-futbolekonomi-raporunu-hazirladi.aspx

- Brands, H., ve Gavin, F. J. (Ed.). (2020). COVID-19 and world order: The future of conflict, competition, and cooperation. Johns Hopkins University Press.

- Breuer, C. (2020). Coronavirus, sports ant the financial cost. Erişim Tarihi: 08.02.2021. https:// www.dw.com/en/coronavirus-sports-and-the-financial-cost/a-52771431

- Burrow, G. (2020). The Economic Impact of COVID-19 on US Sports: Up to \$92.6K Lost Every Minute. Erişim Tarihi: 08.02.2021. https://www.economicmodeling.com/2020/05/28/the-economicimpact-of-covid-19-on-us-sports-up-to-92-6k-lost-every-minute/

- Claeys, A., ve Opgenhaffen, M. (2016). Why practitioners do (not) apply crisis communication theory in practice. Journal of Public Relations Research, 28, 22-247.

- Castillo, A. (2020). COVID-19: WHAT CLUBS AND ATHLETES SHOULD KNOW. Erişim Tarihi: 08.02.2021. https://barcainnovationhub.com/covid-19-what-clubs-and-athletes-should-know/ 
- Chamalidis, M. (2020). How has COVID-19 affected the mental health of athletes? Erişim Tarihi: 08.02.2021.https://tokyo2020.org/en/news/how-has-covid-19-affected-the-mental-health-ofathletes

- Coombs, W. T. (1999). Ongoing crisis communication: Planning, managing, and responding. Thousand Oaks, CA: Sage

- $\quad$ Coombs, W. T. (2010). Parameters for crisis communication. In Coombs, W. T., ve Holladay, S. J. (Eds.), The handbook of crisis communication (pp. 17-53). Malden: Wiley-Blackwell.

- Coombs, W. T. (2014). Ongoing crisis communication: Planning, managing, and responding. Thousand Oaks, CA: Sage

- Cutler, M. (2020). Covid-19 set to halve 2020 sports calendar - new analysis. Erişim Tarihi: 08.02.2021. https://twocircles.com/us-en/articles/covid-to-halve-2020-sports-calendar/

- $\quad$ Çakır, V.O. (2014). Spor Sosyolojisinin Doğuşu; Geleneksel Beden Eğitimi Usul ve Yaklaşımlarında Dönüşüm. (Yayımlanmamış Doktora Lisans Tezi). İstanbul Üniversitesi. İstanbul.

- $\quad$ Demirtaş, A. G. H. (2000). Kriz yönetimi. Kuram ve Uygulamada Eğitim Yönetimi, 23(23), 353-373.

- Devecioğlu, S. (2003, Ekim), Spor Organizasyonlarında Kriz Yönetimi, Beden Eğitimi ve Sporda Sosyal Alanlar Kongresinde sunulan sözel bildiri, Gazi Üniversitesi Beden Eğitimi ve Spor Yüksekokulu, Ankara.

- $\quad$ Ekmekçi, R. (2016). Spor Yönetimine Giriş: Temel Konular. H. Nejat Basım ve Metin Argan (Ed.), Spor Yönetimi için (s. 2 - 32). Ankara: Detay.

- Dixon, E. (2020). CEO Jordi Bertomeu working with partners to minimise financial impact. Erişim Tarihi: 08.02.2021. https://www.sportspromedia.com/news/euroleague-eurocup-basketballcancelled-jordi-bertomeu-coronavirus

- Dring, C. (2020). https://www.gamesindustry.biz/articles/2020-03-28-what-is-happening-withvideo-game-sales-during-coronavirus

- $\quad$ Euroleague (2020). ECA Shareholders Executive Board Announces Decisions Regarding 2019-20 and 2020-21 Seasons. Erişim Tarihi: 08.02.2021. https://www.euroleaguebasketball.net/euroleaguebasketball/news/i/am9neim7ahpbaqym/eca-shareholders-executive-board-announcesdecisions-regarding-2019-20-and-2020-21-seasons

- Flesports.com (2020). Erişim Tarihi: 08.02.2021. VGP Numbers. https://flesports.com/news/vgpnumbers/

- Fearn-Banks, K. (2010). Crisis communication: A casebook approach. Mahwah, NJ: Lawrence Erlbaum Associates.

- $\quad$ FIBA (2020). First ever FIBA Esports Open 2020 a big hit for fans around the world. Erişim Tarihi: 08.02.2021.http://www.fiba.basketball/news/first-ever-fiba-esports-open-2020-a-big-hit-forfans-around-the-world

- $\quad$ Foley (2020). 2020 Esports Survey Report.

- $\quad$ Forbes (2020). 'NHL 20' Decides Finland's Playoff Champion: An Esports Blueprint For A COVID-19 Future? Erişim Tarihi: 08.02.2021. https://www.forbes.com/sites/mattgardner1/2020/05/04/anesports-blueprint-for-a-covid-19-future-nhl-20-decides-finlands-hockey-playoffs/\#333612f4439c

- Gough, C. (2020). https://www.statista.com/statistics/1108307/covid-twitch-youtube-viewers/

- Grove, A. S. (1996). Only the paranoid survive: How to exploit the crisis points that challenge every company and career. Currency. 
- Imam, S.A., Javeed, M., ve Kennedy, J. (2020). Mental Health Manifestations of CovID-19. In Kriz, C., Imam, N., ve Zaidi, S. (Eds.), Breaking Down Covid-19 A Living Textbook (pp. 17-53). Malden: Wiley-Blackwell.

- ISFE (2020). Video Gaming in Lockdown. The impact of Covid-19 on video game play behaviours and attitudes.

- Jacques, T. (2009). Issues and crisis management: quicksand in the definitional landscape. Public Relations Review, 35, 280-286.

- $\quad$ Kerwin, S. (2016). Human resource management in sport. In T. Byers (Ed.), Contemporary issues in sport management: A critical introduction (pp. 135-148). London: Sage.

- $\quad$ Kitchin, P. J., ve Purcell, P. A. (2017). Examining sports communications practitioners' approaches to issue management and crisis response in Northern Ireland. Public Relations Review 43, 661-670.

- Kulüpler Birliği Vakfı (2020). Erişim Tarihi: 08.02.2021. https://twitter.com/kulupler/ status/1259488037123350528

- Lange, D. (2020). UEFA revenue loss for cancelling Euro 2020 due to the coronavirus (COVID-19). Erişim Tarihi: 08.02.2021. https://www.statista.com/statistics/1105619/covid-euro-2020-revenueloss/

- Mastromartino, B., Ross, W. J., Wear, H., ve Naraine, M. L. (2020). Thinking outside the 'box': a discussion of sports fans, teams, and the environment in the context of COVID-19. Sport in Society, 23(11), 1707-1723.

- Medium.com (2019). Sports Industry Report. Erişim Tarihi: 08.02.2021. https://medium.com/qara/ sports-industry-report-3244bd253b8

- Miles, L. ve Shipway, R. (2020). Explorıng the covid-19 pandemic as a catalyst for stımulatıng future research agendas for managing crises and disasters at international sport events. Event Management. 24, 537-552.

- Miyomoto, K. (2020). What postponing the 2020 Olympics means for host city Tokyo. Erişim Tarihi: 08.02.2021. https://www.espn.com/olympics/story/_/id/28948898/what-postponing-2020olympics-means-host-city-tokyo

- NBA (2020). Erişim Tarihi: 08.02.2021. https://twitter.com/NBA/status/1249172416321990660

- News.google.com (2020). Koronavirüs (Covid-19). Erişim Tariih: 08.02.2021.

- $\quad$ Newzoo (2020). The World's 2.7 Billion Gamers Will Spend \$159.3 Billion on Games in 2020; The Market Will Surpass $\$ 200$ Billion by 2023. Erişim Tarihi: 08.02.2021. https://newzoo.com/insights/ articles/newzoo-games-market-numbers-revenues-and-audience-2020-2023/\#: :text=Games,The\%20World's\%202.7\%20Billion\%20Gamers\%20Will\%20Spend\%20\%24159.3\%20Billion\%20 on,Surpass\%20\%24200\%20Billion\%20by\%202023\&text=We\%20forecast\%20that\%202020's\%20 global,year\%20growth\%20of\%20\%2B9.3\%25.

- Nielsen.com (2020a). From 0 to 200 Virtual Nascar Takes Over Esports Amid Sports Blackout. Erişim Tarihi: 08.02.2021. https://www.nielsen.com/us/en/insights/article/2020/from-0-to-200virtual-nascar-takes-over-esports-amid-sports-blackout/

- $\quad$ Nielsen (2020b). La Liga Santander Challenge Report.

- Nielsen (2020c). 3-2-1 Go Video Gaming Is at an All Time High During Covid-19. Erişim Tarihi: 08.02.2021. https://www.nielsen.com/us/en/insights/article/2020/3-2-1-go-video-gaming-is-atan-all-time-high-during-covid-19/

- Premierleague.com (2020). Erişim Tarihi 08.02.2021. https://www.premierleague.com/ news/1662981 
- Öztamur, K. (2019). Kriz İletişiminde Halkla İlişkilerin Fonksiyonel Rolü ve Etkisi. Yüksek Lisans Tezi. Sosyal Bilimler Enstitüsü. Bahçeşehir Üniversitesi.

- PwC (2020). Covid-19 and esports gaming goes mainstream. Erişim Tarihi: 08.02.2021. https:// www.pwc.co.uk/issues/crisis-and-resilience/covid-19/covid-19-and-esports-gaming-goesmainstream.html

- Rietkerk, R. (2020). https://newzoo.com/insights/articles/esports-market-revenues-2020-2021impact-of-covid-19-media-rights-sponsorships-tickets/

- $\quad$ Ruff, P., ve Aziz, K. (2003). Managing communications in a crisis. Gower Publishing, Ltd.

- Silverman, A. (2020). Youth Sports Poll Coronavirus. Erişim Tarihi: 08.02.2021. https:// morningconsult.com/2020/05/13/youth-sports-poll-coronavirus/

- $\quad$ Shipway, R., Miles, L. and Gordon, R. Crisis And Disaster Management For Sport, Routledge, New York, 2021

- $\quad$ Stark, J. (2020). Sports psychologist discusses mental impact of COVID-19 on high school athletes. Erişim Tarihi: 08.02.2021. https://www.3newsnow.com/news/local-news/sports-psychologistdiscusses-mental-impact-of-covid-19-on-high-school-athletes

- $\quad$ Statista (2020). COVID-19: potential ticketing revenue loss for NBA teams 2020. Erişim Tarihi: 08.02.2021. https://www.statista.com/statistics/1114800/coronavirus-ticketing-revenue-loss-nbateams/.

- TDK (2020). Kriz. Erişim Adresi: https://sozluk.gov.tr/

- UEFA (2020). UEFA postpones EURO 2020 by 12 months. Erişim Tarihi: 08.02.2021. https://www. uefa.com/insideuefa/mediaservices/mediareleases/newsid=2641071.html

- $\quad$ Üçüncüoğlu, M., ve Çakır, V. O. (2017). Modern Spor Kulüplerinin Espor Faaliyetlerine İlgi Gösterme Nedenleri Üzerine Bir Araştırma. İnönü Üniversitesi Beden Eğitimi ve Spor Bilimleri Dergisi, 4(2), 34-47.

- $\quad$ WHO(2020a).ErişimTarihi:08.02.2021.https://www.who.int/health-topics/coronavirus\#tab=tab_1

- WHO (2020b). Erişim Tariih: 08.02.2021. https://www.who.int/director-general/speeches/detail/ who-director-general-s-opening-remarks-at-the-media-briefing-on-covid-19---11-march-2020

- Yücel, A. S. (2014). Sporda kriz yönetimi: 3 Temmuz örneği. Akademik Bakış Dergisi, 40, 212-229. 